\title{
É preciso estar louco para acreditar que nos amam?
}

\author{
Mário Eduardo Costa Pereira
}

A paixão comporta em seu cerne uma dimensão de ambigüidade em relação ao sujeito e à existência. Por um lado, como sustenta Hegel, "nada no mundo se fez de grande sem paixão." Por outro, contudo, como alertava Stendhal, "um pouco de paixão aumenta o espírito, demasiada apago-o". Motor da ousadia de viver ou instrumento da loucura e da perdição, a paixão constitui elemento dramático, senão trágico, por excelência. Movidos pela cegueira dos mais elevados ideais, D. Quixotes lançam-se ao combate contra moinhos de vento e partem em busca de suas Dulcinéias inalcançáveis. Arrastado pela desmedida de sua arrogância, pela hybris orgulhosa de desconhecer os limites mortais de sua condição humana, o herói trágico coloca em marcha uma engrenagem diabólica que o conduzirá à sua própria ruína. Definitivamente, não se pode viver sem paixão, mas ela carrega o risco de matar ou de enlouquecer aquele que é por ela arrebatado.

No campo da paixão amorosa, o risco da perda do limite de si mesmo e do outro é ainda mais palpável, embora tal condição de apagamento das fronteiras da singularidade jamais esteja ausente da vida amorosa comum. "Excesso" é o outro nome da paixão amorosa e esta não poderia ser concebida fora do registro do 
transbordante, do arrebatador e do excepcional. A primeira frase de Marco Antônio, em Anthony and Cleopatra de Shakespeare, é justamente: "É pobre o amor que pode ser medido".' Quando, pois, o estado passional deixa de ser o próprio estofo da vida amorosa para transformar-se em seu veneno obsedante?

É da desmedida potencialmente enlouquecedora, própria aos excessos da paixão amorosa, que trata o último livro de Roland Gori, lançado na França em junho do ano passado e intitulado Logique des passions.

Psicanalista e professor universitário, Gori dirige na Universidade de Provence, Aix-Marseille I, o Laboratoire de Psychopathologie Clinique. Esse importante grupo de pesquisas e de formação no campo da psicopatologia é também responsável pela publicação da prestigiosa revista Cliniques Méditerranéennes. Em 2002, Roland Gori, juntamente com Pierre Fédida, Mareike Wolf e outros colegas, criou os SIUERPP (Séminaires Inter-Universitaires Européens de Recherches en Psychopathologie et Psychanalyse), rede de pesquisas que reúne professores e pesquisadores de diversas universidades européias e das mais diversas orientações no campo da psicopatologia. Além disso, ele é membro da Associação Universitária de Pesquisas em Psicopatologia Fundamental. Logique des passions inscreve-se de pleno nesse campo de investigações e interlocuções que coloca o pathos no centro de seus debates.

Ao buscar definir a disciplina por ele próprio criada, Pierre Fédida situa a psicopatologia fundamental na continuidade da tradição trágica grega, que desde os seus primórdios interrogava-se sobre o pathos humano:

Agrada-me repetir que a psicopatologia dispõe de uma prestigiosa tradição filosófica e médica. As interrogaçōes colocadas sobre a experiência humana - tais como as descobrimos tanto nos textos literários e filosóficos, quanto nos antigos tratados médicos - testemunham precisamente da atenção lançada à vida secreta dos homens, à função do cérebro, às doenças da alma e do corpo, ao papel político da cidade. às paixões trágicas do amor e do ódio, da vida e da morte, enfim, ao fato de pertencer a uma filiação. Trata-se de dizer que a psicopatologia coloca no cerne de sua consciência trágica o pathos que o poeta Ésquilo evocava no Agamemnon nesses termos du pathei mathos - o que se aprende do sofrimento. (Fédida, 2000, tradução minha)

Nesse sentido, o livro do professor Gori constitui uma contribuição inestimável ao campo da psicopatologia fundamental, aprofundando e radicalizando uma investigação psicopatológica do pathos amoroso, que ilumina, a partir da psicanálise, a própria delimitação do objeto psicopatológico.

1. Mark Antony. There's beggary in the love that can be reckon'd.

Anthony and Cleopatra, Ato I, Cena I. 
Em certo sentido, em Logique des passions Roland Gori dá continuidade - agora sob nova perspectiva - a uma investigação sistemática das relações entre loucura e paixão, iniciada em seu livro anterior $A$ prova pela fala: sobre a causalidade em psicanálise (1998). Ali, o psicanalista francês tratava em especial da "paixão da causalidade", dando-se como ponto de partida a seguinte questão: "por que, face a seus problemas de saúde, certos indivíduos experimentam a necessidade de apelar para explicações de ordem psíquica?" (p. 166). Para respondê-la, Gori havia recorrido ao paradigma da psicose, tal como elaborado no célebre artigo de Tausk (1919) intitulado "Da gênese do 'aparelho de influenciar' na esquizofrenia". Tendo esse clássico da literatura psicanalítica sobre a psicose como referência teórica principal, Roland Gori propõe que o "aparelho" descrito por Tausk constitui uma construção delirante permitindo ao paciente localizar e determinar o sentido e a causa do que com ele acontece, restituindo uma certa coerência a seu mundo existencial despedaçado: "[Este] é o modelo paradigmático de todas as concepções psicologizantes dos sintomas" (Gori, 1998, p. 167). Tais racionalizações delirantes conseguem se impor, apesar de sua artificialidade, graças a uma "paixão da causalidade", que busca garantir ao sujeito a existência de "uma ordem divina das coisas", fiadora a priori do sentido do mundo.

Em Logique des passions, o problema psicopatológico das paixões é retomado dessa vez sob a perspectiva dos extremos da paixão amorosa.

A paixão de Fabrice e Béatrice, apresentada no prólogo do livro, ilustra de maneira eloqüente a condição de extremo arrebatamento amoroso que o autor se propõe a examinar. Esses dois amantes mergulham na experiência desesperada do louco amor, em que a própria continuidade da existência depende da garantia de que a entrega mútua será completa, absoluta, sem reservas. A presença do Outro nessa relação é indesejável e profundamente ameaçadora: "É apenas quando os dois estão completamente a sós, um com o outro, que se sentem bem. Tudo o que não é eles permanece estrangeiro e ameaçador. O 'outro', sob sua mínima forma, a mais anônima, traz o risco de estabelecer uma fissura nessa união" (p. 20).

A marca distintiva dessa paixão é a de que cada um dos parceiros exige do outro o abandono total e sem reservas a esse amor absoluto. A ruptura de todas as fronteiras entre os amantes visa a constituição de uma totalidade plena, concretizando no eixo do tempo o projeto de uma "eternidade fusional" (p. 17).

Estabelece-se, assim, por parte da dupla, um distanciamento completo das questões práticas da banal vida cotidiana. Gori retoma esse aspecto de enclausuramento protetor em seu neo-universo idealizado, justamente para lembrar que "na paixão, o senso comum não desempenha qualquer papel, seja no início, seja no fim. É mesmo porque o senso comum foi colocado entre parênteses, que a paixão existe. É sua própria condição" (p. 27). 
Trata-se, portanto, da expressão daquilo que a paixão amorosa comportz de mais absorvente, de mais fusional, de mais desesperado em sua ânsia por formar "Um": pleno em sua completude, sem falhas e sem fissuras, isolado das dores e incertezas do mundo. O texto tem portanto, por objeto teórico, a paixã amorosa que enlouquece por sua aspiração à totalidade, à unificação com o objetc amado.

O autor lembra que o termo "paixão" evoca em primeiro lugar as dimensões de sofrimento, de padecimento. Remete igualmente a algo da ordem do sofrimento torturante do amor e do desejo. Nessa mesma perspectiva, o pathos grego diz respeito, antes de mais nada, ao padecido, ao sofrido.

Seria, contudo, a paixão algo do mesmo registro que o amor? Deve-se atentar que a paixão comporta a dimensão aniquilante do "morrer de amor". Ou seja, estamos aqui em um registro que implica o excesso, a perda dos limites, o risco da dissolução no outro. Nesse sentido, a paixão remete ao risco do fusional enquanto dissolução mortífera da própria subjetividade e exigência de entrega absoluta por parte do outro.

Tal mergulho na experiência fusional, e tal exigência de total cumplicidade do outro nesse projeto, trazem ao primeiro plano dos estados passionais o risco do abandono. E quanto mais agudo for o sofrimento que tal risco comporta, mais urgente e necessária se faz uma retórica da plenitude. A grandeza transcendente e absoluta dessa modalidade de relacionamento deve ser constantemente ressaltada e glorificada, de modo a reassegurar os parceiros de sua propriedade e de sua continuidade.

Quando o sujeito não tem mais dúvidas e que a convicção de ser amado coloca-se no horizonte da completude sem falhas, o estado passional atinge seu paroxismo patológico descrito por Clérambault: a síndrome erotomaníaca dos delírios passionais. Todos os componentes do chamado "Postulado Fundamental" encontram-se presentes, oriundos das raízes arcaicas dessa paixão originária: "foi o objeto que começou, que ama mais ou é o único que ama". A mãe sedutora primordial que, nos sonhos do sujeito, considerava-o seu objeto absoluto de desejo, encontra-se aí re-editada.

Gori salienta, então, a dimensão profundamente narcísica implicada nos excessos da paixão amorosa. O objeto da paixão é constituído menos pelos traços daquilo que fomos, do que pela referência a um objeto ideal que jamais tivemos e que jamais fomos.

O estado passional retoma uma paixão originária: o arrebatamento da criança diante do espelho, ao constatar - pleno de exaltação - de que se trata ali de sua própria imagem, uma imagem amada, valorizada e narcisicamente investida pelo Outro. 
A proposição passional - "Eu quero ser tudo para ti" - reflete, loucamente, em espelho, "a procura ilusória em nome da qual o sujeito, na aurora de sua existência, fora seduzido pelas palavras maternas: - Tu és tudo para mim" (Gori, 2002, p. 38). Correlativamente, a paixão amorosa engaja uma dimensão fetichista na relação com o objeto amado: "Faço de mim o fetiche do Outro". Em algum momento, passo a sentir-me no lugar do falo do Outro, o que corresponde à resposta especular à demanda de amor absoluto implicada no "Quero ser tudo para ti".

O autor recorre, assim, a Clérambault no sentido de delimitar um núcleo erotomaníaco fundador da experiência passional, o que o leva a perguntar se é preciso ser louco para se acreditar que se é amado. A dimensão psicótica, em todo caso, não é estrangeira ao âmbito da paixão. Por um lado, o apagamento das separações que singularizam o sujeito, aproximam-no da vivência enlouquecedora da despersonalização. Ao mesmo tempo, completamente alienado ao campo desse pequeno outro de sua paixão, o sujeito expõe-se, impotentemente, ao maior dos riscos: o do abandono.

Nessa perspectiva, Roland Gori propõe que a paixão amorosa implica aquilo que André Breton denominava "o delírio da presença absoluta" (p. 34): como aspiração, como solução e como dissolução. E é também tal estado de coisas que confere à vivência de ciúmes, freqüentemente extrema - e mesmo delirante - dos estados passionais, o estatuto de uma tentativa de cura, em todo caso, um esforço para sustentar uma separação: talvez eu não seja tudo para o outro. $\mathrm{O}$ ciúme constituiria um esforço de subjetivação conduzindo o indivíduo a sair desse estado mortífero da ordem da erotomania. Em outros termos, trata-se de uma tentativa de cura da completude delirante proporcionada pela experiência erotomaníaca. O ciúme obriga a aceitação de uma cruel realidade: "Eu não sou o único para ela"; correlativa de outra, potencialmente libertadora: "Ela não é tudo para mim". O arcaico infantil evidencia-se na terrível, mas decisiva constatação que constitui a condição de possibilidade para o próprio desejo: "Eu não sou tudo para minha mãe".

$\mathrm{Na}$ verdade, o apaixonado ignora - e mesmo esforça-se por ignorar - o que se passa consigo próprio, sufocando a própria falta por meio da promessa de completude oferecida pela fusão imaginária com o outro amado. O processo da paixão comporta, portanto, um elemento de desmentido: "A falta é contingente e estou prestes a superá-la definitivamente, dissolvendo-me no meu(na minha) amado(a)".

O desamparo - a Hilflosigkeit descrita por Freud - surge aqui como o próprio fundamento da paixão. Ou ainda, dito de outra forma, a louca paixão amorosa constitui um dos destinos possíveis da descoberta não subjetivada da própria condição de desamparo. Nesse sentido, o processo passional é um esforço 
para se reconstruir uma paixão originária idealizada que jamais existiu, mas cuja plenitude é suposta superar definitivamente o próprio desamparo.

Dessa maneira, a separação e a falta, longe de serem as simples conseqüências da ruptura amorosa, na verdade a precedem e são sua própria condição de existência. A paixão é um dos destinos possíveis para o traumatismo não subjetivado decorrente dessa descoberta do desamparo: a paixão cria um objeto-tela que funciona como máscara de Nada.

Gori traz então uma constatação de caráter empírico, e mesmo clínico: é freqüentemente de um estado triste que sobrevém o arrebatamento passional. Pode-se, pois, levantar a hipótese de que a paixão constitui uma das máscaras da melancolia.

A paixão constitui uma ilusão produzida por uma coincidência entre uma ilusão e um pedaço de realidade; entre uma expectativa e uma realização. Em outras palavras, o processo passional depende de um feliz encaixe entre um fragmento da realidade que consiste em ver no outro algo que garanta a própria completude e dissimule o desamparo com a expectativa alucinatória de sua realização no processo fusional. O apaixonado entrega-se, pois, a uma experiência sacrificial, mergulhado que está em sua aspiração a uma fusão absoluta com o outro. Sem revelar-se como tal, a expectativa de ruptura de todos os limites em relação ao objeto de sua paixão constitui uma aspiração à morte ou, pelo menos, uma aspiração mortífera próxima ao que Winnicott descreveu como medo do colapso - fear of breakdown - o indivíduo vive sob a égide do terror da possibilidade de uma catástrofe de abandono e de separaçāo, que na verdade já ocorreu.

O mergulho no estado de apaixonamento depende, pois, de um contato com o próprio desamparo, ou seja, trata-se de alguém que de algum modo conheceu o desespero da ausência do outro e da necessidade de responder por si mesmo sobre um fundo de absoluta falta de garantias transcendentes. Dessa forma, a paixão nasce sobre um fundo de perda e de desamparo.

Freud sustenta que não somos amados pelo outro enquanto sujeitos, mas fundamentalmente na condiçāo de objeto. Trata-se de uma tenebrosa constatação: é na condição de objeto do Outro que somos constituído e essa talvez seja a mais radical experiência de desamparo e de solidão. A erotomania surge nesse contexto como esforço desesperado para preencher o vazio instalado por essa constatação.

No sentido contrário, o ódio comporta uma dimensão realista, ou realizante. O Outro passa a ser visto tal como ele é. Em outros termos, o ódio instala-se nas situações em que $o$ sujeito vê-se obrigado a abandonar muito rapidamente sua ilusão de completude e ter de lidar com a concretude da realidade e do mundo exterior antes de dispor dos meios para fazê-lo efetivamente. Constitui um esforço 
de reconstrução da realidade, destruída pela presença excessivamente opressora e invasiva do Outro.

O processo analítico, por sua vez, mantém uma estreita relação com o estado passional. A clínica mostra que, à medida que a análise vai implantando sua obra de desconstrução do sentido, ocorre a tendência ao aparecimento da paixão no âmbito da transferência. Roland Gori interpreta esse fenômeno como expressando a necessidade, por parte do sujeito, da criação de um fiador para seu mundo simbólico em vias de desestabilização, ao mesmo título do que vai acontecendo com sua auto-imagem narcísica e sua própria experiência erótica corporal. É precisamente nesse contexto de abalo dos fundamentos do mundo simbólico, explicitados no sofrimento do sintoma, e no descortinamento do próprio desamparo, que termina por fazer apelo a um Sujeito-Suposto-Saber, chamado a decifrar o enigma do sujeito e a restaurar uma economia desiderativa organizada dentro dos limites do princípio do prazer. Surge, assim, uma transferência propriamente psicanalítica. Contudo, o horror e a contundência de tal constatação, especialmente nos momentos próximos ao término de uma análise podem fazer recrudescer um desespero arcaico que encontra, na condição de ser tudo para o outro, a única possibilidade de sobrevivência.

Logique des passions constitui um livro em si mesmo apaixonante, documento indispensável para todo aquele interessado pelo estudo das paixões e pelo campo da psicopatologia fundamental e para o qual o público brasileiro espera - o mais brevemente possível - conhecer a tradução para o português.

\section{Referências}

FéDidA, P. Adresse du Professeur Pierre Fédida au Veme Congrès de Psychopathologie Fondamentale. Comunicação lida na abertura do $5^{2}$ Congresso Brasileiro de Psicopatologia Fundamental, realizado em Campinas, set./2000.

GoRı, R. A prova pela fala: sobre a causalidade em psicanálise. São Paulo: Escuta/ Universidade Católica de Goiás, 1998.

Logique des passions. Paris: Denoël, 2002.

Shakespeare, W. Antônio e Cleópatra. Trad. de Bárbara Heliodora. Rio de Janeiro: Lacerda Ed., 2000, p. 20.

TAUSK, V. (1919). Da gênese do "aparelho de influenciar na esquizofrenia". In: TAUSK, V., KaTZ, C. \& Birman, J. (Org.). Tausk e o aparelho de influenciar na psicose. São Paulo: Escuta, 1990, p. 37-77. 